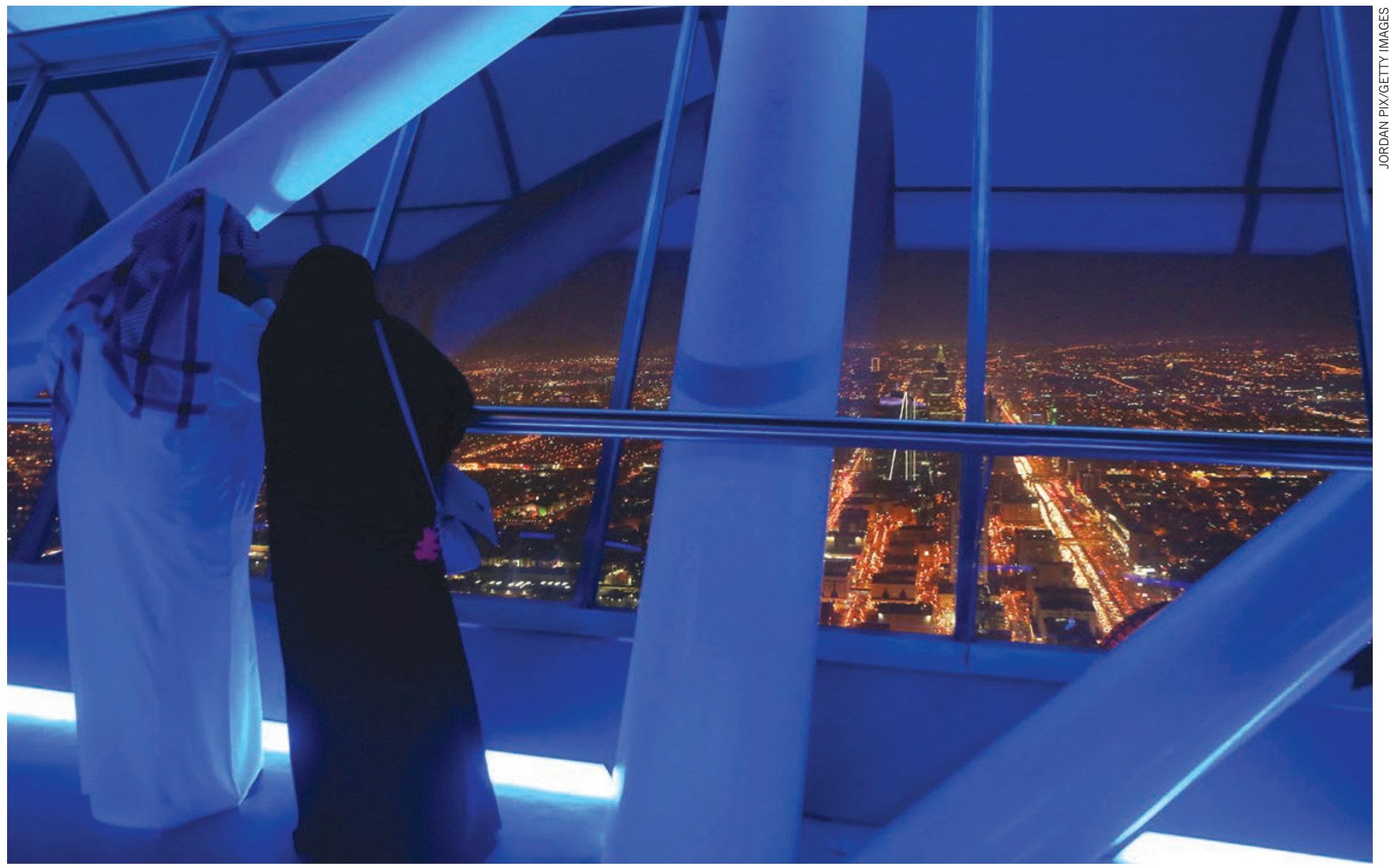

A view from the Kingdom Tower in Riyadh, the Saudi Arabian capital and a main centre for the country's renewed commitment to science.

\title{
A 21ST CENTURY TRANSFORMATION
}

\section{Saudi Arabia has a bold plan to diversify from its oil industry to create a knowledge economy.}

\section{BY SEDEER EL-SHOWK}

A $s$ the world searches for viable energy sources as alternatives to fossil fuels, Saudi Arabia is striving to diversify in order to secure its future prosperity and reduce its economic reliance on oil. In 2002, the Saudi government established the National Science, Technology and Innovation Policy (NSTIP), an ambitious long-term strategic framework to manage the nation's scientific development and transition to a knowledge-based economy. More than US $\$ 6$ billion was allocated to the first phase of the NSTIP, which ran from 2008 to 2014.

The Kingdom's effort to become a knowledge-based economy is spearheaded by its national science agency, the King Abdulaziz City for Science and Technology (KACST), which is responsible for implementing the NSTIP. Ambitious initiatives launched by KACST, such as the Saudi Human Genome Project, have expanded the country's scientific reach.

Saudi Arabia's research landscape has also been transformed by the growth of the King Abdullah University of Science and Technology (KAUST), a graduate-level research university founded on the shores of the Red Sea in 2009, modelled on the structure of Western universities such as Caltech. Mohamed Eddaoudi, chair of KAUST's chemical science programme and associate director of its Advanced Membranes and Porous Materials Research Center, believes the university provides an example

\section{"What the} Kingdom of Saudi Arabia accomplished in the past few years went beyond our expectations. The challenge now is to meet the new goals." for other countries in the region, a demonstration that "excellent research can be performed effectively and efficiently anywhere in the world if bright minds are given the world-class tools necessary to be competitive".

The Nature Index reflects the fruits of these developments. Over the last four years, Saudi Arabia has seen its presence in the index expand rapidly. Its weighted fractional count (WFC), which measures the contribution of authors to scientific papers tracked by the index, has more than doubled, making the Kingdom the eighth largest riser in WFC globally. In 2015, 21 Saudi Arabian institutions were affiliated with authors publishing their research in the Nature Index journals.

\section{NEW FIELDS OF DISCOVERY}

Being the world's largest oil exporter, it comes as no surprise that petroleum industries dominate the Saudi Arabian economy, with the oil sector accounting for around half of the country's US $\$ 750$ billion GDP and the vast majority of its exports. This focus inevitably instructs the country's research priorities. The bulk of Saudi Arabia's WFC has come from the chemical and physical sciences, which together constitute almost $90 \%$ of the country's output in the Nature Index in 2015. In 


\section{TOP 10 GLOBAL RISERS}

This map shows the top 10 countries that have experienced the largest increase of their WFC from 2012 to 2015 worldwide. The circle sizes are relative to this increase. China leads the way having jumped from a WFC of 4,523 in 2012 to a WFC of almost 6,481 , an increase of 1,958 .

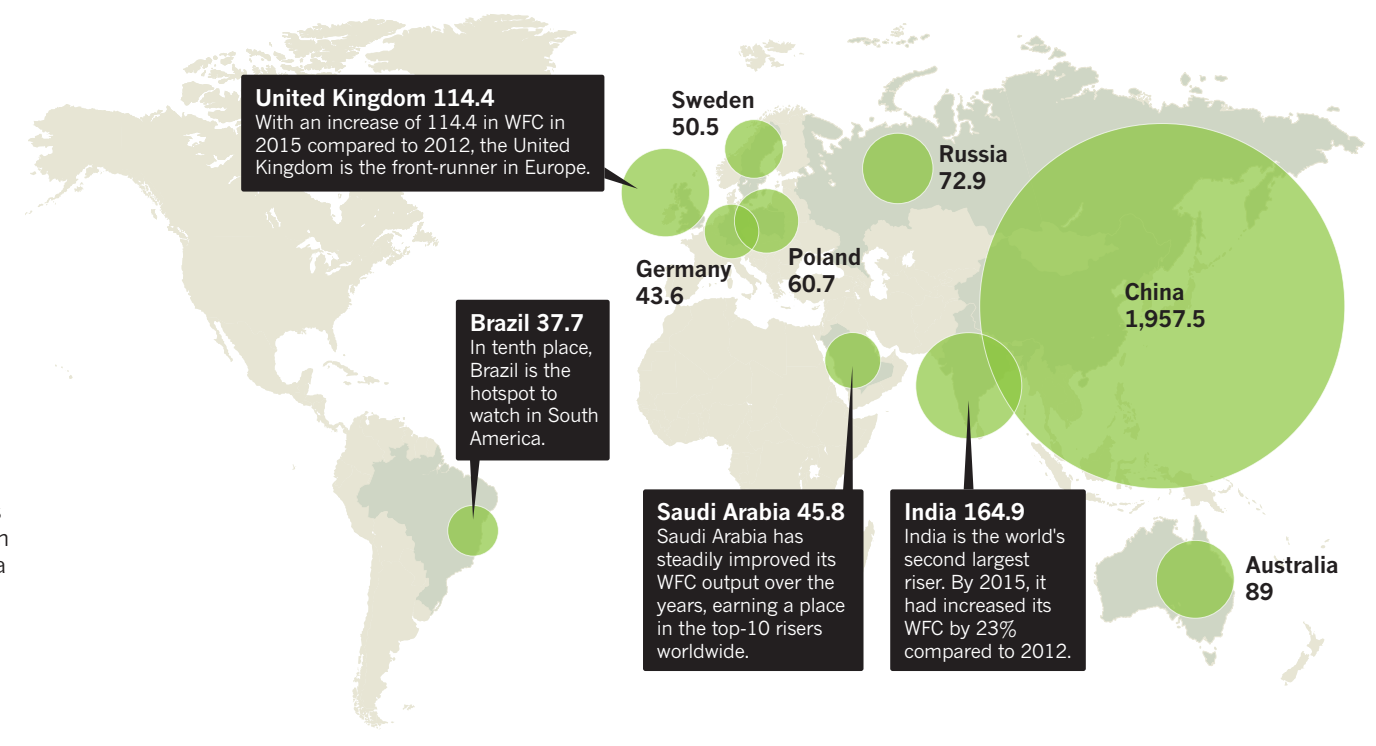

\section{SAUDI ARABIA'S RESEARCH STRENGTHS}

Saudi Arabia's overall research output (WFC) in the Nature Index has grown, but different subject areas have experienced varying patterns of growth.

Chemistry

Earth \& environmental sciences

Life sciences

Physical sciences
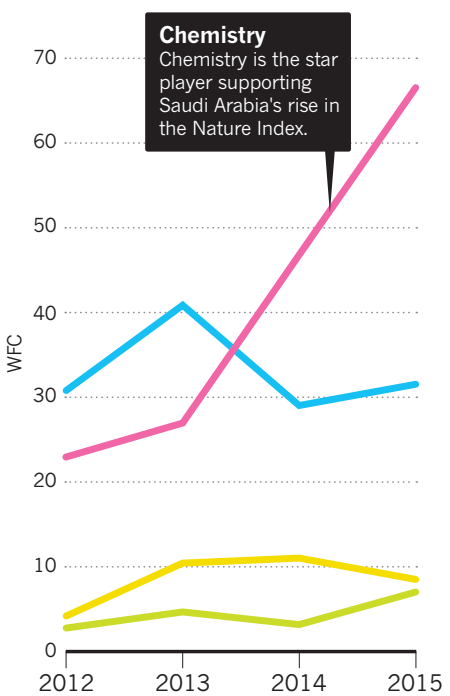

\section{SPOTLIGHT ON} LIFE SCIENCES

Often overshadowed by Saudi Arabia's achievements in chemistry and physical sciences, life science research in the Kingdom is beginning to come into its own, with the help of these institutions contributing to its life sciences output in 2015

KAUST

KAU

KFSH\&RC

KSU

KFUPM

Others

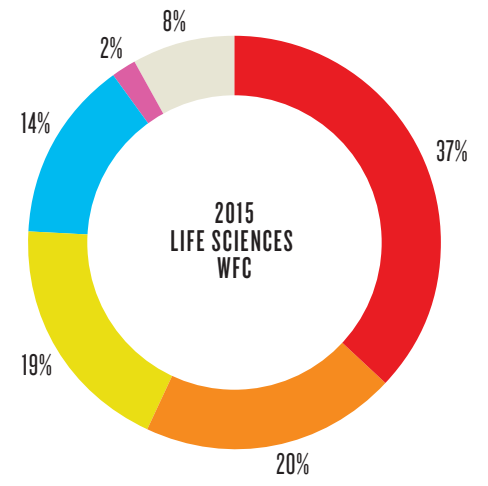

particular chemistry has seen a rapid rise over the years, overtaking the physical sciences as the top subject area in 2014 and continuing to expand in 2015. The effort to shift the country towards a knowledge-based economy has capitalized on these strengths, bringing rewards from research projects in advanced material sciences, nanotechnology and photonics.

Despite the country's overt focus on chemistry, it has also been increasing its output in the life sciences as well as in Earth and environmental sciences. Since 2012, contribution to life science papers in the index has doubled, with much of this increase being driven by research at KAUST and the King Faisal Specialist Hospital and Research Centre (KFSH\&RC).

KFSH\&RC, which focuses almost exclusively on life science research, has been increasing both the number of papers with a KFSH\&RC affiliated author as well as the contribution they make. In 2012, its researchers contributed to only four papers that count within Saudi Arabia's article count (AC). This jumped up to 15 papers in 2015. Its overall contribution, as measured by WFC, has also seen an increase over the years, particularly marked from 2012 to 2013.

"This is due to a strong research platform built of talented researchers, excellent technical capabilities and proper oversight to ensure that our work is done at the highest standards," explains Sultan Al-Sedairy, executive director of KFSH\&RC. "The primary propeller was the availability of funding through the NSTIP from KACST." Al-Sedairy also directs the Saudi Human Genome Project, which has driven domestic collaborations and enabled local researchers to publish higher impact papers.

Geneticist Fowzan Alkuraya, a specialist in disease gene discovery, joined KFSH\&RC in 2007 after training in the United States. Since then, he has built an extensive network of collaborators throughout the Middle East who connect him with significant patients. "We got access to whole-exome sequencing in 2011, and that's when my lab's gene-discovery pipeline really took off. Instead of discovering a couple of genes per year, we now discover at least one or two genes per week," he says. Through the Saudi Human Genome Project, his team has free and mostly unlimited access to next-generation sequencing.

KAUST has also seen dramatic growth in its life sciences output, with a more than threefold increase in its WFC from 2012 to 2015. "It's the nature of the research. Getting results in biology takes several years, and KAUST was only established in 2009, so this is about the earliest you'd expect to start seeing a significant number of publications in high-profile journals," says Pierre Magistretti, dean of KAUST's Division of Biological and Environmental Sciences and Engineering.

Magistretti explains that his division is focusing on a few key areas in order to maximize the impact of its research. While researchers in KAUST's academic divisions are free to pursue basic research, the university also has 11 research centres that focus on applied research in areas of national importance, such as water desalination, desert 

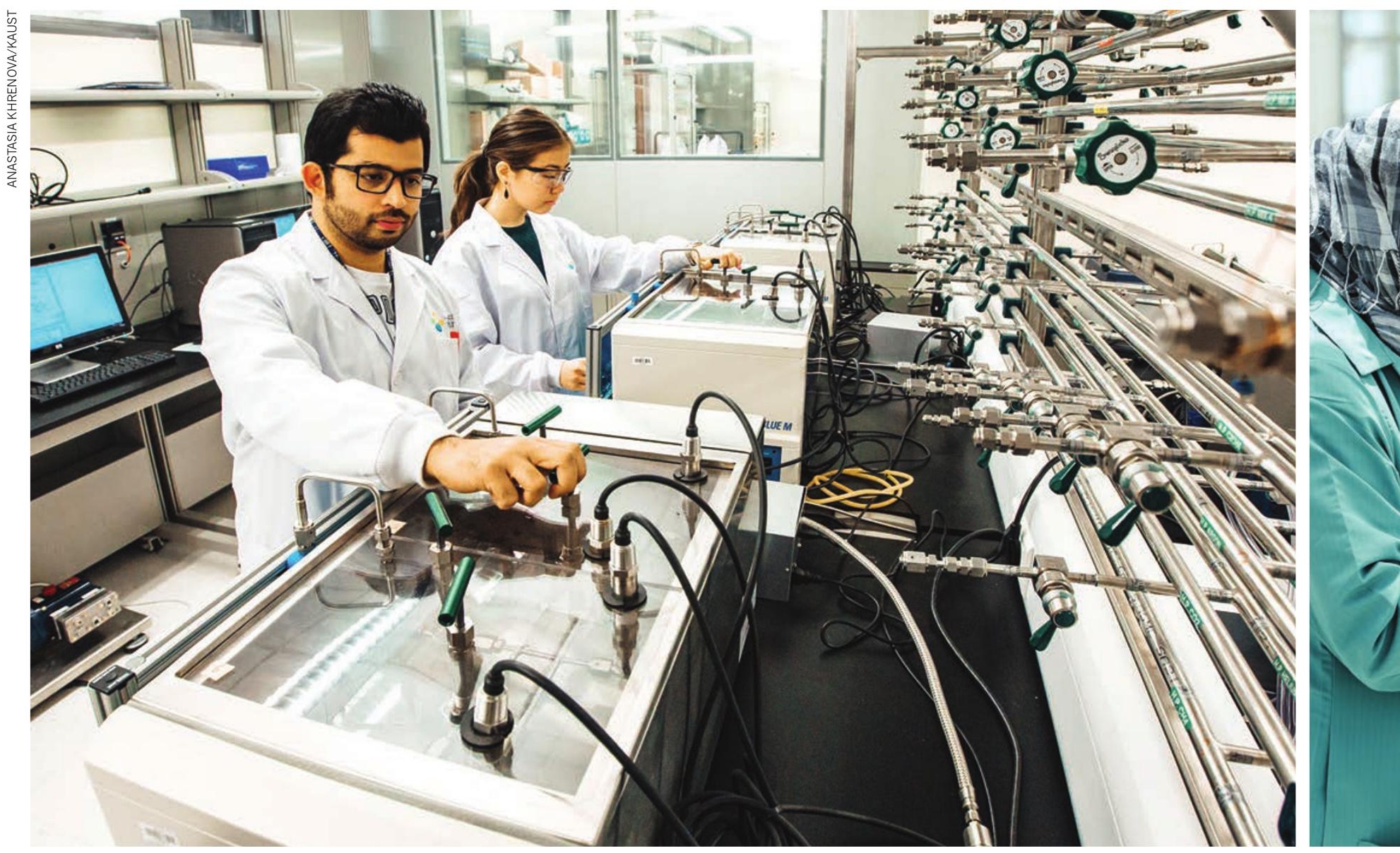

Researchers at KAUST'S Advanced Membranes and Porous Materials Research Center, whose work aims for efficient desalination of seawater and wastewater treatment.

agriculture, and solar energy.

In addition to cultivating local talent, KAUST encourages productive collaborations. "It's important that the principal investigators are active and fully based here, but they can enhance their potential with collaborators from outside," says Magistretti. Principal investigators awarded grants through the university's Competitive Research Grants programme can share a percentage of the funds with collaborators if they participate in the grant application, offering an incentive to build international networks.

\section{NURTURING LOCAL TALENT}

KAUST's research output in the Kingdom is rivalled only by King Abdulaziz University (KAU), but the two show vastly different patterns of collaboration. Since 2013, KAUaffiliated authors have produced increasingly more articles than KAUST, but its contribution to these papers has remained relatively low by comparison. This may indicate that many of its publications resulted from collaborations in which it played only a small part. KAUST may have contributed to fewer articles, but its overall WFC of 72 in 2015 eclipses KAU's 14. It accounts for $73 \%$ of Saudi Arabia’s institutional WFC. By pulling their weight in collaborations, institutes such as KAUST and KFSH\&RC not only enhance Saudi Arabia's scientific reputation, they also help build the local talent and capability that is crucial to the Kingdom's goal of a knowledge-based economy.

"It was just a matter of time before we saw local students as lead authors in top-tier journals," says Eddaoudi. "A female Saudi student was the lead author on a high-profile paper my group recently pub"More than $60 \% \quad$ lished where $95 \%$ of of the biology the work was done students at at KAUST, and the KAUST are only outside activfemalle. And ity was the use of a many of them synchrotron facilare Saudi." ity in Europe." The paper, published in the Journal of the American Chemical Society in 2015, describes a metal-organic framework which can be used to store methane at room temperature and low pressures, an important step towards the efficient use of the gas as a clean, alternative fuel.

The knowledge and skills that come from scientific training may be particularly beneficial to Saudi Arabian women, who are the subject of heavy cultural restrictions in the Kingdom. "More than $60 \%$ of the biology students at KAUST are female, and many of them are Saudi," says Magistretti. "I think this is something very positive."

The total number of Saudi students studying abroad increased to 200,000 in 2013, says Mansour Alghamdi, director of scientific awareness and publishing at KACST. The Kingdom also benefits from a significant knowledge transfer by students returning home. Alghamdi explains that many return to Saudi Arabia as researchers who continue to publish with their former supervisors, while improving experience levels domestically.

\section{A CHALLENGING TRANSITION}

Despite these accomplishments, the transition to a knowledge-based economy has a long way to go, with oil and petroleum-related industries continuing to play the central role in Saudi Arabia. The prioritization of scientific research has yet to be reflected in the country's R\&D budget, which was equivalent to only $0.3 \%$ of the GDP in 2015 according to a report by Battelle, though the NSTIP calls for an increase to $1.6 \%$ of GDP by 2020 .

In addition, $R \& D$ spending by private firms, though not monitored, is estimated to be very low by international standards, according to Mohammad Khorsheed, the secretary general 

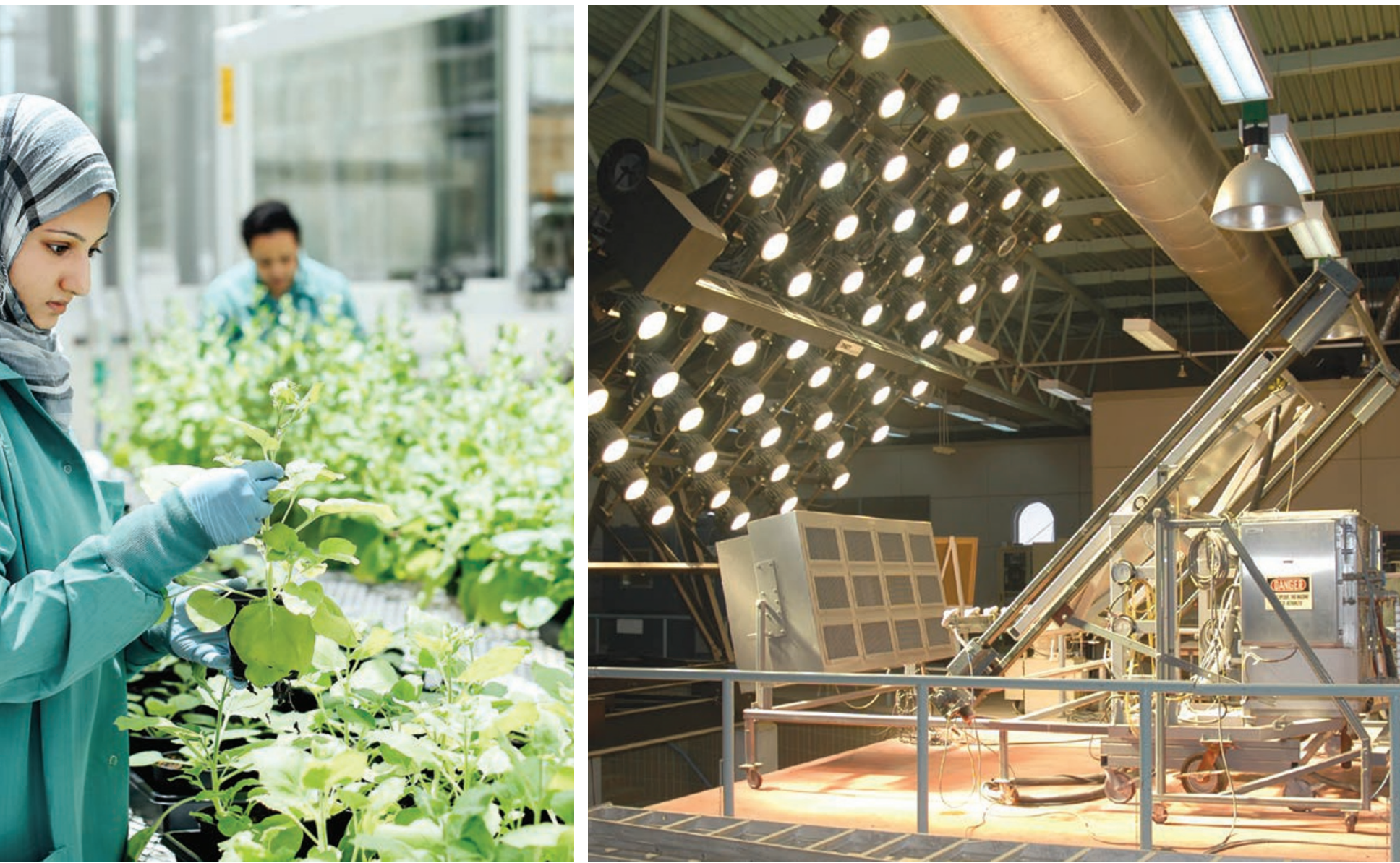

KAUST'S Center for Desert Agriculture (left) looks at such possibilities as drought resistant crops and one of the laboratories in KACST's solar village, located 35-km north of Riyadh (right).

of the steering committee for the Saudi Innovation Ecosystem. Khorsheed also highlights social resources as a challenge facing the Kingdom. A knowledge-based economy thrives in a knowledge-based society, yet Khorsheed cites public apathy about science and a lack of interest in education. Only 23 people out of 100,000 work in research and development, and only one in 1,000 people aged 20 to 34 are science and engineering graduates, less than a tenth of the proportion of such graduates in an average population of an EU country. Brain drain, which sees the brightest people of a population leave, also poses a problem, with $25 \%$ of science, technology, engineering and mathematics (STEM) graduates emigrating annually.

But, officials remain optimistic. Alghamdi does not think a lack of human resources will be a significant issue due to Saudi Arabia's "unprecedented expansion in higher education in the last few years," going on to cite OECD predictions that the Kingdom will see a six-fold increase in tertiary degrees by 2030 .

KAUST's gifted student programme identifies promising students in the penultimate year of high school to spend a summer at KAUST and then travel to the United States on a KAUST fellowship after they graduate. The students spend a foundation year learning

about the American system before applying to top universities, and after completing their undergraduate studies return to KAUST for graduate studies. "It's a valuable programme and could produce remarkably qualified students," says Magistretti.

\section{TOWARDS A KNOWLEDGE-BASED ECONOMY}

With strong financial support and young scientists like Alkuraya returning from abroad, there's little doubt that Saudi universities will continue to improve their research output as labs mature.

The first phase of the NSTIP saw Saudi researchers establish local infrastructure while engaging in collaborations worldwide. "Some of the collaborations were not very successful, but there are lessons to be learned from them. Besides transferring technology to the Kingdom, there are

"Some of the collaborations were not very successful, but there are lessons to be learned from them. challenge by building a framework to support innovation in Saudi Arabia. He notes that despite their abundant liquidity, Saudi investors tend to be risk-averse and reluctant to put funds into young, technology-driven companies.

In an effort to overcome this, KACST has established the BADIR Program for Technology Incubators, which aims to encourage innovative startups. Several companies have already graduated from the incubator programme, including a company which developed a surgical dressing for diabetic foot ulcers out of an industrial waste product from prawn shells.

The second phase of the NSTIP, which began in 2015 and runs until 2019, calls for Saudi Arabia to build on the developments in its national infrastructure and capabilities to make the country a regional leader in science, technology and innovation. This will require a continued focus on research and patent production, coupled with a strong programme to transfer technology to the private sector and an intensive effort to develop the Kingdom's human resources.

"What the Kingdom of Saudi Arabia accomplished in the past few years went beyond our expectations," says Alghamdi. "The challenge now is to meet the new goals of the coming stages." 
KAUST

2015 WFC: 72.06 2015 AC: 174

2015 NATURE INDEX GLOBAL RANKING: 174

\section{COMING OF AGE}

The King Abdullah University of Science and Technology (KAUST) was established by the late King Abdullah in 2009 with an endowment of US $\$ 20$ billion to provide a state-of-the-art institution for skilled, passionate scientists to carry out cutting-edge research. The university was envisioned as a modern-day House of Wisdom, the influential intellectual centre of the Islamic Golden Age (which ran from the ninth until the thirteenth century).

Located on the Red Sea coast, the campus includes extraordinary core facilities which provide the infrastructure necessary for world-class research. "Scientists here at KAUST are expected to do something that makes a difference," explains Pierre Magistretti. Principal investigators are encouraged to secure grants, but are also offered generous baseline funding to give them the freedom to pursue original research that could result in breakthrough discoveries.

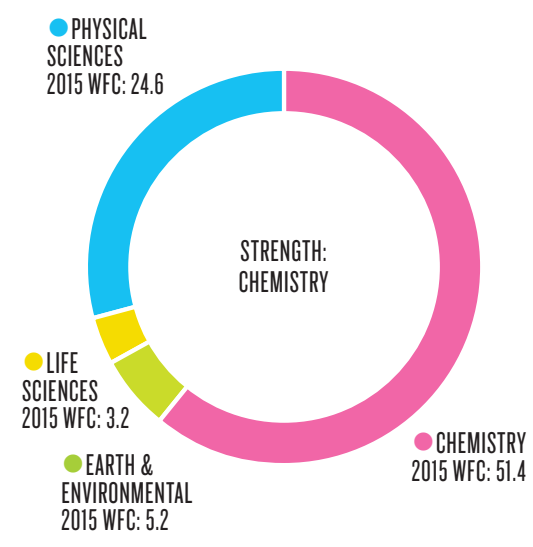

-Subjects may overlap. The sum of subject area WFCs may therefore exceed the institution's overall WFC.
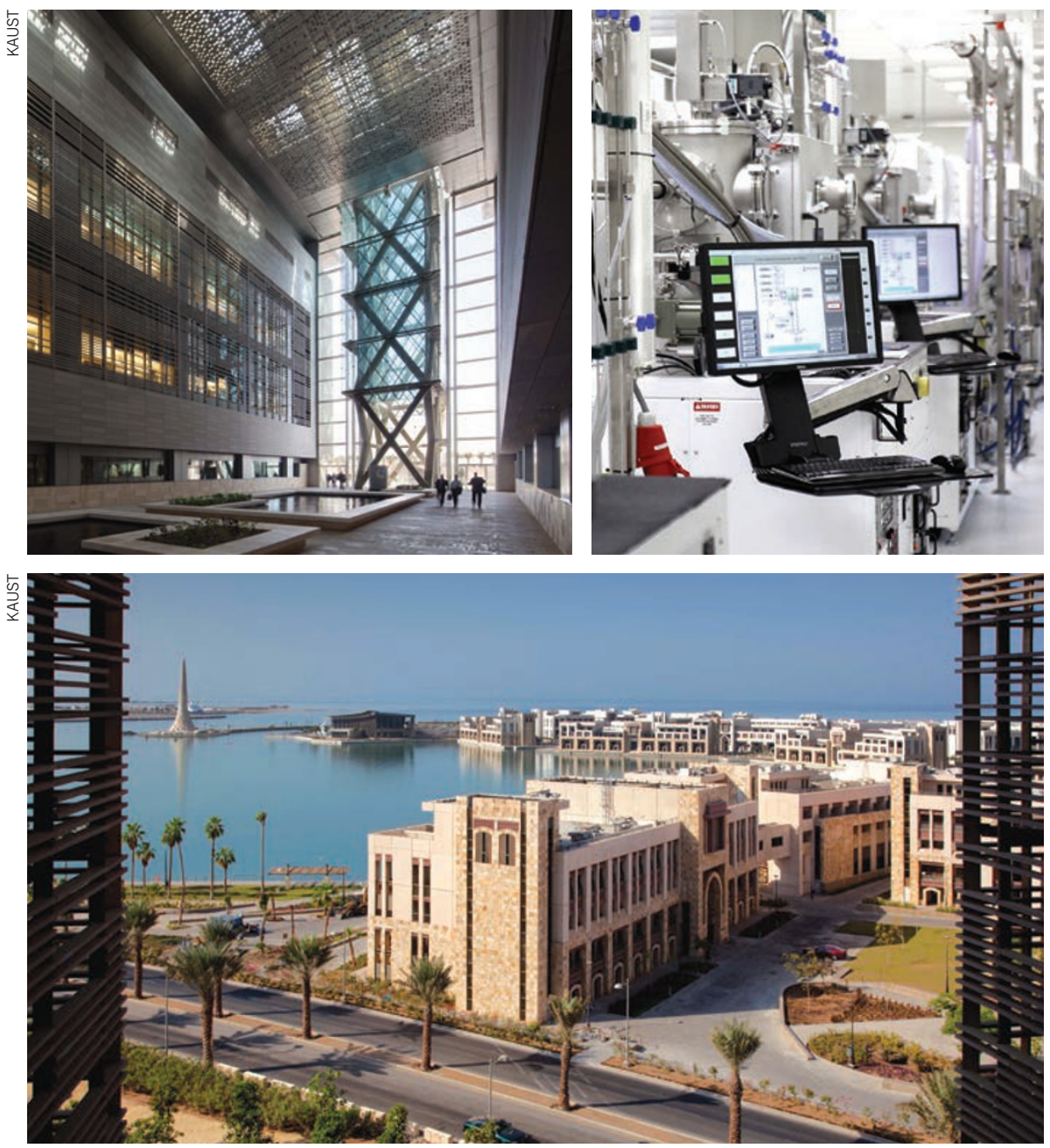

KAUST's core labs on its modern campus on the Red Sea, which acts as a natural lab for marine studies.
KAU

2015 WFC: $14.43 \quad 2015$ AC: 216

2015 NATURE INDEX GLOBAL RANKING: 601

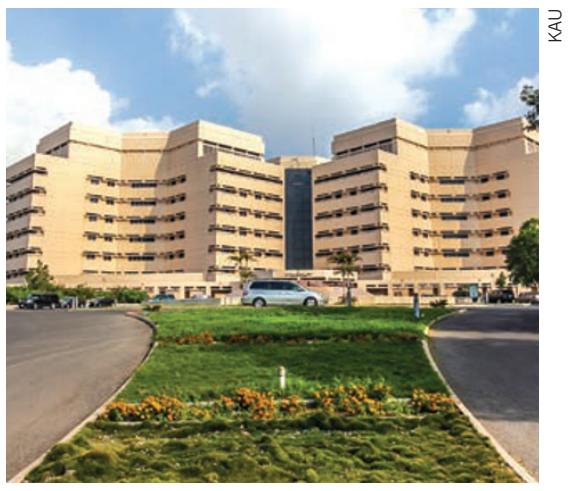

KAU campuses are single-gender.

\section{BUILDING BRIDGES}

King Abdulaziz University is one of the leading institutes in the Kingdom, with more than 80,000 students at its single-gender campuses. KAU nearly tripled its total output, as measured by WFC, in journals in the index between 2012 and 2015, however, it still heavily depends on external collaborations which have continued strongly over the past few years.

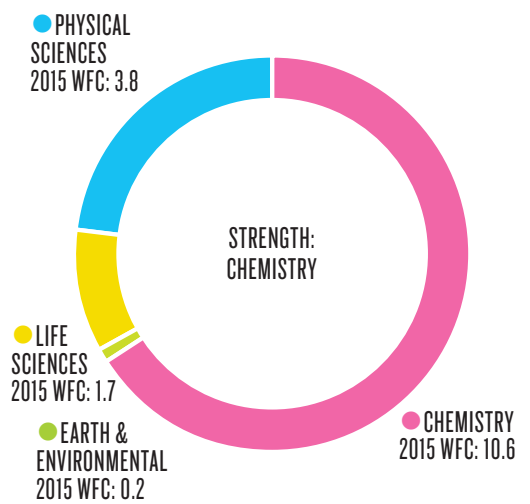

"Our Distinguished Scientists programme has enabled hundreds of international collaborators to visit, research and lecture, increasing collaboration with universities worldwide," explains Adel Alahmadi, KAU's general supervisor for scientific affairs. In future the university wants to increase funding directed at local cooperation, while remaining focused on high-impact research. "Solving local problems will be given a higher priority, with research groups led by prominent local researchers getting stronger support." 
KSU

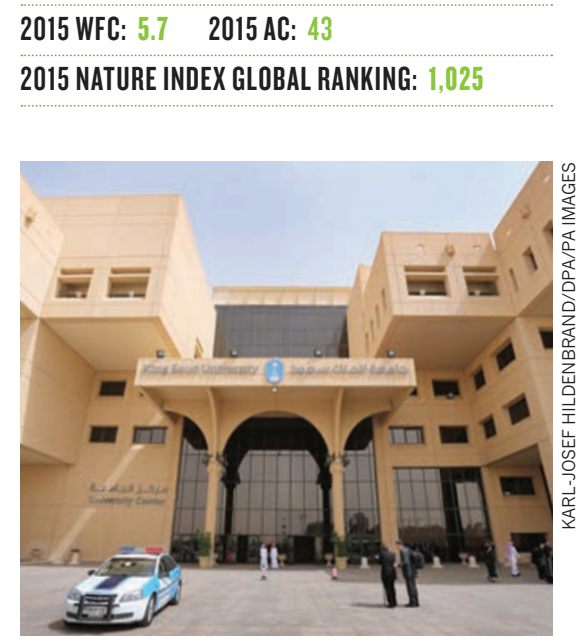

King Saud University in Riyadh.

\section{A LOCAL LEADER}

Established in 1957, King Saud University was Saudi Arabia's first university. It accounts for about a quarter of the country's scientific output and, until 2014, produced more papers annually than any other institute in the Kingdom, when it was overtaken by King Abdulaziz University. Despite its leading role in the country, KSU ranks behind

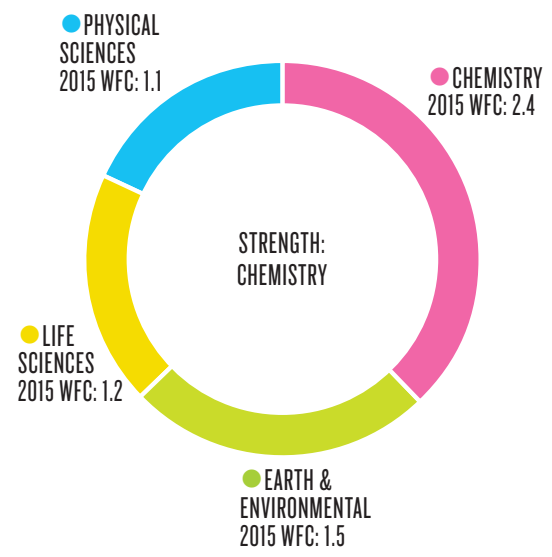

KAUST and KAU in the Nature Index because of the focus of its research strategy.

"In support of the NSTIP, KSU targets key research areas which involve use-inspired research, and these areas generally do not conform to the list of journals tracked by the Nature Index," explains Rshood Khraif, KSU's dean of scientific research. "In addition, much of our research output is produced as articles or books published in Arabic, which don't get indexed by the Web of Science."
KACST

2015 WFC: 1.712015 AC: 22

2015 NATURE INDEX GLOBAL RANKING: 1,732

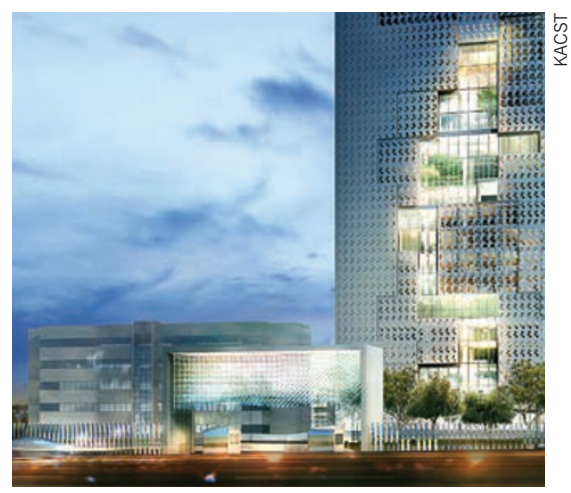

An impression of KACST's Maarifah centre.

\section{A GUIDING FORCE}

The King Abdulaziz City for Science and Technology (KACST) serves as the Kingdom's national laboratories and its science agency. While its direct output accounts for only a small fraction of Saudi Arabia's AC, it plays a central role in coordinating and facilitating research across the nation. KACST is responsible for managing the country's science policy, funding research, and building and

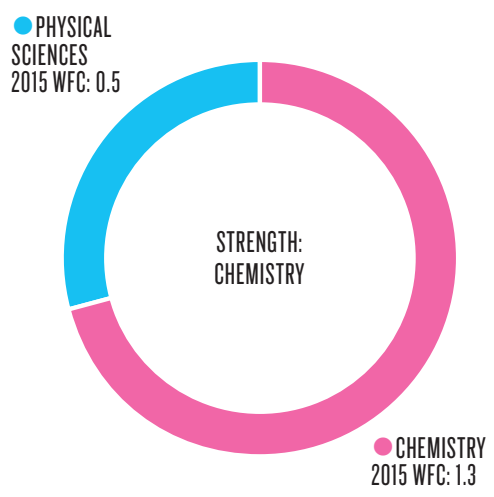

maintaining the infrastructure to support scientific research.

"We identified what the most important areas of research for Saudi Arabia are, and plan how we need to address each of these to reach a knowledge economy," says Abdulaziz Al-Swailem, vice-president for scientific research support at KACST.

It has established research centres focused on a wide range of topics, as well as major initiatives such as the Saudi Human Genome Project. It also promotes commercialization of research via projects such as the BADIR Program for Technology Incubators through its Technology Development Center.
KFSH\&RC

2015 WFC: $1.64 \quad 2015$ AC: 15

2015 NATURE INDEX GLOBAL RANKING: 1,762

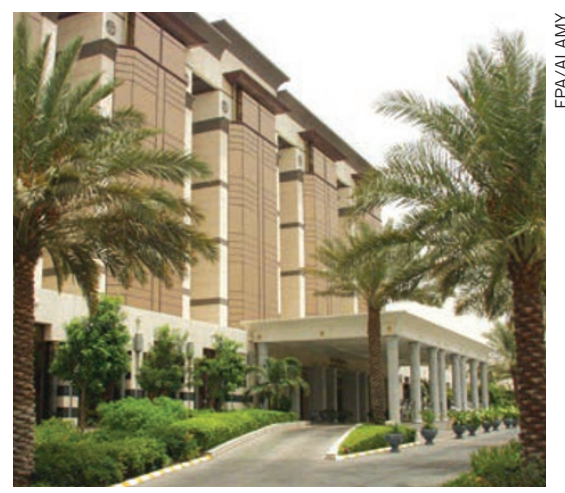

King Faisal Specialist Hospital in Jeddah.

\section{GENES AND GENOMES}

Established in 1975, the King Faisal Specialist Hospital and Research Centre is one of Saudi Arabia's leading medical and academic institutes. It serves as the national referral and research centre for oncology, organ transplants, cardiovascular conditions and genetic diseases.

KFSH\&RC is also home to one of the Saudi Human Genome Project's highthroughput sequencing labs. More than

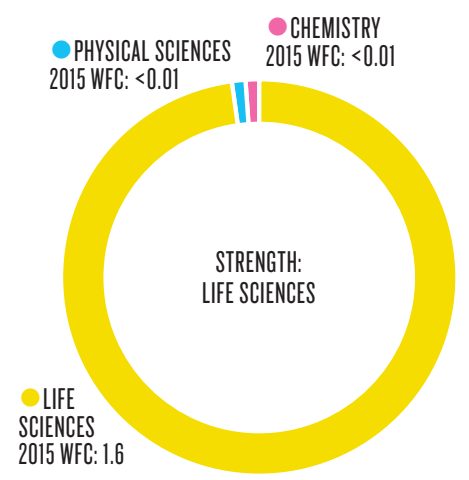

half of marriages in Saudi Arabia are between relatives, which results in high rates of genetic disease in the Kingdom. This prevalence provides a backdrop of rich research opportunity to discover the genes behind these diseases. Researchers at KFSH\&RC have created a 'gene panel' which tests 3,000 genes to identify genetic disorders in patients.

"There's a very strong clinical and research interaction," says Sultan Al-Sedairy. "As a result, we have an elite institution researching unique pathologies with the capability to provide samples that are clinically well-defined and then dissect them genotypically." 